\title{
Definition of the Labile Capping Bond Effect in Lanthanide Complexes
}

\author{
Aurora Rodríguez-Rodríguez, ${ }^{[a, b]}$ Martín Regueiro-Figueroa, ${ }^{[a]}$ David Esteban-Gómez, ${ }^{[a]}$ Teresa \\ Rodríguez-Blas, ${ }^{[a]}$ Véronique Patinec, ${ }^{[b]}$ Raphaël Tripier, ${ }^{*},[b]$ Gyula Tircsó, ${ }^{[c]}$ Fabio Carniato, ${ }^{[\mathrm{d}]}$ Mauro \\ Botta, ${ }^{*},[\mathrm{~d}]$ and Carlos Platas-Iglesias, *,[a]
}

\begin{abstract}
We report two novel macrocyclic ligands containing a cyclen unit, a methyl group, a picolinate arm and two acetate pendant arms attached to two nitrogen atoms of the macrocycle either in trans $\left(1,7-\mathrm{H}_{3}\right.$ Medo2ampa) or in cis $\left(1,4-\mathrm{H}_{3}\right.$ Medo2ampa) positions. These ligands provide eight-coordination to the $\mathrm{Ln}^{3+}$ ions leaving a coordination position available for a water molecule that occupies a capping position in the twisted square antiprismatic polyhedron $\left(1,4-\mathrm{H}_{3}\right.$ Medo2ampa) or one of the positions of the square antiprism (1,7- $\mathrm{H}_{3}$ Medo2ampa). The charge neutral [Gd(1,7-Medo2ampa)] complex presents an unprecedentedly low water exchange rate $\left(k_{\mathrm{ex}}{ }^{298}=8.8 \times 10^{3} \mathrm{~s}^{-1}\right)$, while water exchange in [Gd(1,4-Medo2ampa)] is three orders of magnitude faster $\left(k_{\mathrm{ex}}{ }^{298}=\right.$ $\left.6.6 \times 10^{6} \mathrm{~s}^{-1}\right)$. These results showcase the labile capping bond phenomenon: a ligand occupying a capping position is hindered by the environment and thus is intrinsically labile.
\end{abstract}

\section{Introduction}

Exchange reactions involving water molecules in the first and second solvation shells of metal complexes are of fundamental importance to understand the reactivity of metal ions in both chemical and biological systems. ${ }^{[1]}$ Indeed, the replacement of a coordinated water molecule by an entering ligand represents a key step in the formation of metal complexes in aqueous solutions ${ }^{[2]}$ and in many redox processes. ${ }^{[3]}$ The mean residence times of coordinated water molecules in aquated complexes spread over 20 orders of magnitude from ca. 300 years for

[a] Dr. A. Rodríguez-Rodríguez, Dr. M. Regueiro-Figueroa, Dr. D. Esteban-Gómez, Prof. T. Rodríguez-Blas, Dr. C. Platas-Iglesias Centro de Investigaciones Científicas Avanzadas (CICA) and Departamento de Química Fundamental, Facultade de Ciencias, Universidade da Coruña, 15071 A Coruña, Galicia, Spain. E-mail: carlos.platas.iglesias@udc.es

[b] Dr. V. Patinec, Prof. R. Tripier

Université de Bretagne Occidentale, UMR-CNRS 6521, UFR des Sciences et Techniques, 6 avenue Victor le Gorgeu, C.S. 93837 , 29238 Brest Cedex 3, France.

E-mail: Raphael.Tripier@univ-brest.fr

[c] Dr. G. Tircsó

Department of Inorganic and Analytical Chemistry

University of Debrecen

H-4010 Debrecen, Egyetem tér 1, Hungary

[d] Dr. F.Carniato, Prof. M.Botta

Dipartimento di Scienze e Innovazione Tecnologica, Università del

Piemonte Orientale "A. Avogadro", Viale T. Michel 11, 15121

Alessandria, Italy.

E-mail: mauro.botta@uniupo.it

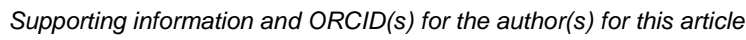
are available on the WWW under gttp://dx.doi.org/.
$\left[\operatorname{lr}\left(\mathrm{H}_{2} \mathrm{O}\right)_{6}\right]^{3+}$ to only $\sim 200 \mathrm{ps}$ for the extremely labile $\left[\mathrm{Eu}\left(\mathrm{H}_{2} \mathrm{O}\right)_{7}\right]^{2+}$ (at $25 \stackrel{\circ}{\circ} \mathrm{C}) .{ }^{[4,5]}$

The water exchange reactions in the aquated lanthanide ions $\left[\mathrm{Ln}\left(\mathrm{H}_{2} \mathrm{O}\right)_{q}\right]^{3+}(q=8$ or 9$)$ have been investigated by Merbach et al. using ${ }^{17} \mathrm{O}$ NMR techniques. ${ }^{[6]}$ Among the different $\mathrm{Ln}^{3+}$ ions, $\mathrm{Gd}^{3+}$ complexes have attracted particular attention during the last 20 years due to their increasing use as contrast agents (CAs) in clinical and pre-clinical magnetic resonance imaging (MRI) procedures. ${ }^{[7]}$ CAs are paramagnetic compounds, often small $\mathrm{Gd}^{3+}$ chelates, which accelerate the relaxation rates of water molecules in the surrounding tissues. ${ }^{[8]}$ Water exchange dynamics plays a key role in determining the effectiveness of $\mathrm{Gd}^{3+} \mathrm{CAs}$, as exchange of the bound water molecule(s) should be sufficiently fast to attain optimal relaxivities. ${ }^{[9]}$ On the other hand, extremely slow water exchange rates in $\mathrm{Ln}^{3+}$ complexes have been exploited to design CAs based on the Chemical Exchange Saturation Transfer (CEST) approach, which represent an attractive alternative to the classical $\mathrm{Gd}^{3+}$-based agents. ${ }^{[10]}$ CEST agents based on $\mathrm{Ln}^{3+}$ ions typically contain a pool of exchangeable protons in intermediate-to-slow condition with the bulk water $\left(k_{\mathrm{ex}} \leq \Delta \omega\right)$. Application of a presaturation pulse at the frequency of the exchangeable protons (i. e. a coordinated water molecule) induces the transfer of some saturated spins into the water pool, thereby attenuating the signal of bulk water. ${ }^{[11]}$

The residence time of a water molecule in the inner coordination sphere of $\mathrm{Gd}^{3+}$ complexes $\left(\tau_{\mathrm{m}}{ }^{298}\right)$ expands over a range of about four orders of magnitude from the longest determined for dota-tetraamide derivatives $\left(\tau_{\mathrm{m}}{ }^{298}=8-20 \mu \mathrm{s}\right)^{[12]}$ to the shortest measured for the aqua ion ${ }^{[13]}$ and a $\mathrm{Gd}^{3+}$ complex with an octadentate ligand containing phosphonate groups $\left(\tau_{\mathrm{m}}{ }^{298}\right.$ 1.3-1.4 ns). ${ }^{[14]}$ In the case of $\mathrm{Eu}^{3+}$-based CEST agents appropriate ligand modifications allowed to attain residence times as long as $150-700 \mu \mathrm{s}^{[15,16]}$

Among the different factors that have been identified to accelerate the water exchange of the coordinated water molecule in $\mathrm{Gd}^{3+}$ (or $\mathrm{Eu}^{3+}$ ) complexes are: i) increasing the negative charge of the complex, ${ }^{[17]}$ and ii) increasing the steric compression around the water coordination site. ${ }^{[18]}$ Both effects facilitate the departure of the coordinated water molecule in a dissociative process, which is the most common mechanism responsible for the water exchange reaction in nine-coordinate $\mathrm{Gd}^{3+}$ complexes. ${ }^{[1]}$ On the contrary, the inclusion of hydrophobic units around the water binding site minimizes hydrogen-bonding between the coordinated water and the second coordination sphere, which results in slower water exchange rates. ${ }^{[16,19]}$ The wider and more extensive number of studies have focused on monoaqua nine-coordinated complexes. Many of these are 
derivatives of dota in which the water molecule occupies the apical position, capping the upper square face of the antiprism. A common and effective strategy for improving the effectiveness of a $\mathrm{Gd}^{3+}$-chelate as MRI probe is to increase the hydration state from one $(q=1)$ to two $(q=2)$. In dota-like derivatives, this implies the presence of one water molecule in the axial position and of a second water molecule in an equatorial position, orthogonal to the first. An obvious yet still unanswered question concerning the water exchange dynamics of these systems arises: Have the two water molecules similar rates of exchange or do they behave independently?

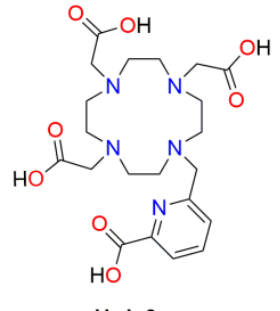

$\mathrm{H}_{4}$ do3ampa

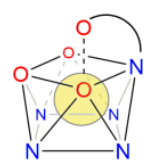

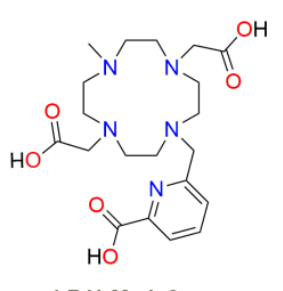

1,7- $\mathrm{H}_{3}$ Medo2ampa

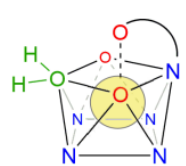

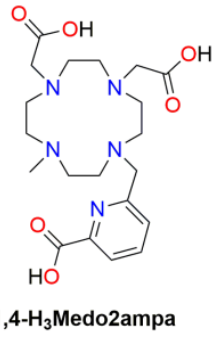

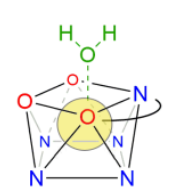

Scheme 1. Ligands discussed in the present work and their expected coordination mode after complexation with $\mathrm{Gd}^{3+}$.

Thus, we sought to design a pair of ligands for $\mathrm{Ln}^{3+}$ complexation having an identical number and type of donor atoms, while providing complexes containing a coordinated water molecule either occupying a position in the coordination polyhedron or a capping position. This was accomplished using as a starting point the $\mathrm{H}_{4}$ do3ampa ligand (Scheme 1), ${ }^{[20]}$ which was shown to form nine-coordinate complexes in solution where the oxygen atom of the picolinate group occupies the capping position in a capped square antiprismatic (SAP) coordination polyhedron. We hypothesized that removing one the carboxylate groups in trans position to the picolinate arm to give $1,7-\mathrm{H}_{3}$ Medo2ampa should result in the coordination of a water molecule in one of the square faces of the coordination polyhedron, with the capping position being occupied by the oxygen atom of the picolinate group. On the contrary, removal of a carboxylate group in cis position with respect to the pyridyl unit should allow picolinate to lean on the methyl group, permitting a water molecule to occupy a capping position. Thus, we report the synthesis of the 1,7- $\mathrm{H}_{3}$ Medo2ampa and 1,4- $\mathrm{H}_{3}$ Medo2ampa ligands, and demonstrate the labile capping bond effect with a detailed analysis of the water exchange rates in the corresponding $\mathrm{Gd}^{3+}$ complexes. The discovery of this effect provides new strategies to modulate ligand exchange rates in $\mathrm{Ln}^{3+}$ complexes, with great potential impact in the coordination chemistry of the $4 \mathrm{f}$ elements.

\section{Results and Discussion}

Synthesis of the ligands and metal complexes. The synthetic protocol used for the preparation of 1,7- $\mathrm{H}_{3}$ Medo2ampa is shown in Scheme 2. Cyclen glyoxal $\mathbf{1}$ was obtained following the literature procedure by direct condensation of glyoxal with cyclen. ${ }^{[21]}$ The subsequent trans-alkylation of $\mathbf{1}$ with benzyl bromide gave compound 2, ${ }^{[2]}$ which was deprotected under basic conditions to give compound $\mathbf{3}$ with an overall yield of $93 \%$ over the three steps. Reaction of $\mathbf{3}$ with tert-butyl bromoacetate in acetonitrile in the presence of $\mathrm{K}_{2} \mathrm{CO}_{3}$ afforded compound 4 in satisfactory yield $(72 \%)$. The benzyl groups of 4 were removed by Pd-catalyzed hydrogenolysis to yield compound $\mathbf{5}$ quantitatively. Monoalkylation of $\mathbf{5}$ with $\mathrm{Mel}$ to give the key intermediate 6 was then achieved with $92 \%$ yield. The careful selection of the reaction conditions was critical for the preparation of this compound in high yield. In particular, yields were found to increase significantly when the reaction was carried out at low temperature $\left(0{ }^{\circ} \mathrm{C}\right)$, the concentration of precursor 5 in the reaction medium was not too high $(<0.02 \mathrm{M})$ and Mel was added slowly to the solution of $\mathbf{5}$. Alkylation of 6 with the 6-chloromethyl derivative $7^{[23]}$ followed by the deprotection of the methyl and tert-butyl ester groups provided the 1,7- $\mathrm{H}_{3}$ Medo2ampa ligand, which was isolated as the hydrochloride salt with an overall yield of $50 \%$ as calculated from cyclen (8 steps). The hydrochloride salt was then converted to the trifluoroacetate salt by treating the former with trifluoroacetic acid.

Reaction of 1,7- $\mathrm{H}_{3}$ Medo2ampa with lanthanide triflates in the presence of an excess of triethylamine resulted in the formation of the charge neutral complexes of formula [Ln(1,7-Medo2ampa) $\left.\left(\mathrm{H}_{2} \mathrm{O}\right)\right](\mathrm{Ln}=\mathrm{La}, \mathrm{Eu}, \mathrm{Gd}, \mathrm{Tb}, \mathrm{Yb}$ or $\mathrm{Lu})$, which were isolated in $85-90 \%$ yields. The high resolution mass spectra $\left(\mathrm{ESI}^{+}\right)$show peaks due to the [ $\left.\mathrm{Ln}(1,7-\mathrm{HMedo2ampa})\right]^{+}$ entities, thereby confirming the formation of the complexes (Figures S17 to S22, Supporting Information).

The synthesis of $1,4-\mathrm{H}_{3}$ Medo2ampa (Scheme 3 ) started by conversion of cyclen glyoxal $\mathbf{1}$ into the methylated derivative $\mathbf{9}$ by reaction with Mel $(97 \%)^{[22]}$ followed by the deprotection with hydrazine hydrate $(87 \%)$. Subsequently, compound 10 was alkylated with compound 7 , affording the cis derivative 11, which was used without further purification in the next step. Previous studies showed that the regioselective "cis" alkylation of cyclen was dependent both on the steric hindrance of electrophiles and solvent system. ${ }^{[2]}$ The regioselective alkylation of 10 was achieved in acetonitrile at $0{ }^{\circ} \mathrm{C}$. Finally, reaction of 11 with tertbutyl bromoacetate in acetonitrile in the presence of $\mathrm{K}_{2} \mathrm{CO}_{3}$ followed by deprotection of the methyl and tert-butyl ester groups with $6 \mathrm{M} \mathrm{HCl}$ provided the 1,4- $\mathrm{H}_{3}$ Medo2ampa ligand in its hydrochloride salt form. The overall yield over the six steps required to prepare the ligand starting from cyclen was $31 \%$. The [Ln(1,7-Medo2ampa)] complexes were prepared in aqueous solution by mixing equimolar amounts of the ligand and lanthanide chlorides or triflates, followed by adjustment of the $\mathrm{pH}$ to 7.0. The HR-MS $\left(\mathrm{ESI}^{+}\right)$confirm the formation of the complexes. 
<smiles>C1CCNCCNCCNC1</smiles>

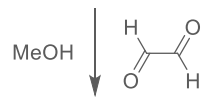<smiles>C1CN2CCN3CCN4CCN(C1)C2C34</smiles>

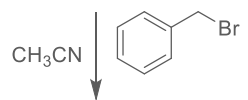

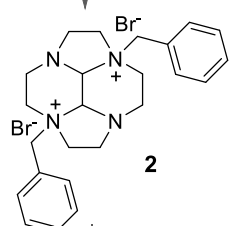<smiles>C=CCCN(CCNCCN(CCNCC)Cc1ccccc1)Cc1ccccc1</smiles>

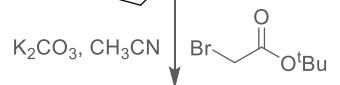<smiles>[18OH]</smiles><smiles>CCOC(=O)CNCCN(CCN(CCN(CC(=O)O)Cc1ccccc1)CC(=O)O)Cc1ccccc1</smiles>

Scheme 2. Synthesis of $1,7-\mathrm{H}_{3}$ Medo2ampa

Structural analysis. The ${ }^{1} \mathrm{H}$ NMR spectrum of the paramagnetic [Yb(1,7-Medo2ampa)] complex (Figure 1) shows 25 of the 26 paramagnetically shifted signals expected for a single species having a $C_{1}$ symmetry in solution. The most shifted axial protons of the cyclen ring are observed at $88.9,82.3,56.0$ and $47.7 \mathrm{ppm}$. These values are very similar to those observed previously for the [Yb(do3ampa)] complex (99.7, 78.8, 61.5 and $57.0 \mathrm{ppm}) .^{20}$ The latter compound was demonstrated to adopt a square antiprismatic (SAP) structure in solution by analysis of the $\mathrm{Yb}^{3+}$-induced ${ }^{1} \mathrm{H}$ NMR shifts. Thus, we conclude that the [Yb(1,7-Medo2ampa)] complex adopts a SAP structure in solution as well, which is confirmed by the relative energies of the two isomers obtained using DFT calculations (Supporting Information).

The ${ }^{1} \mathrm{H}$ NMR spectrum of the $[\mathrm{Yb}(1,4-$ Medo2ampa)] complex (Figure 1) reveals the presence of two complex species in solution, which provide two sets of signals with different intensities. The most shifted axial proton of the minor species $(\sim 30 \%)$ is observed at $135.8 \mathrm{ppm}$, which is characteristic of a (SAP) coordination around the metal ions. ${ }^{[25]}$ Thus, the speciation of $[\mathrm{Yb}(1,4-$ Medo2ampa $)]$ in solution is dominated by the twisted-square antiprismatic (TSAP) isomer ( 70\%).
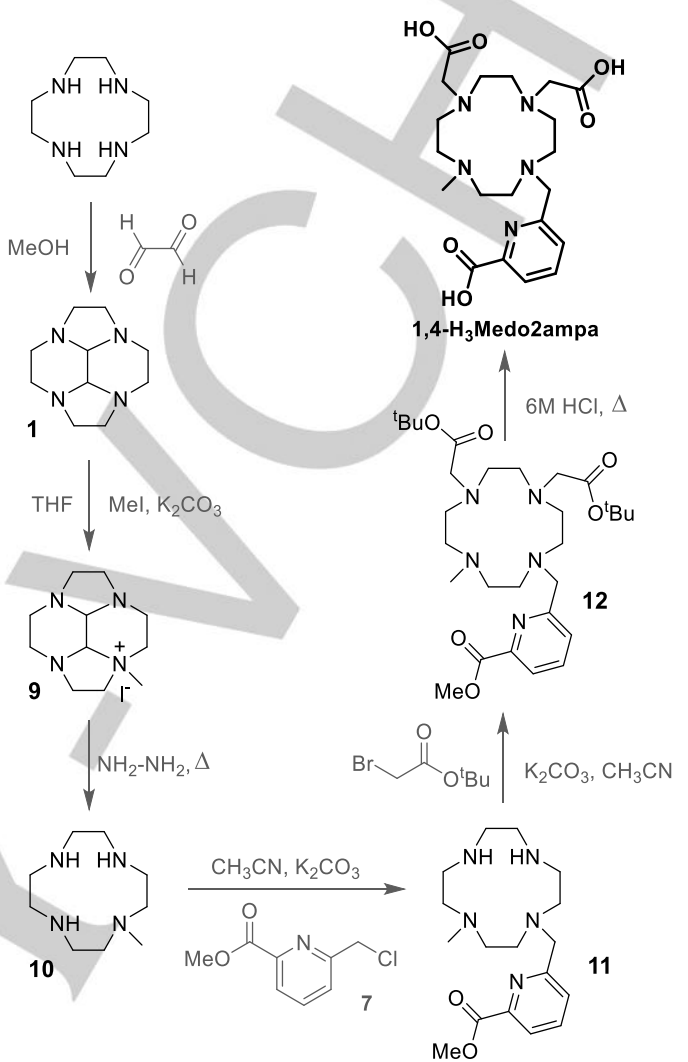

Scheme 3. Synthesis of $1,4-\mathrm{H}_{3} M e d o 2 a m p a$

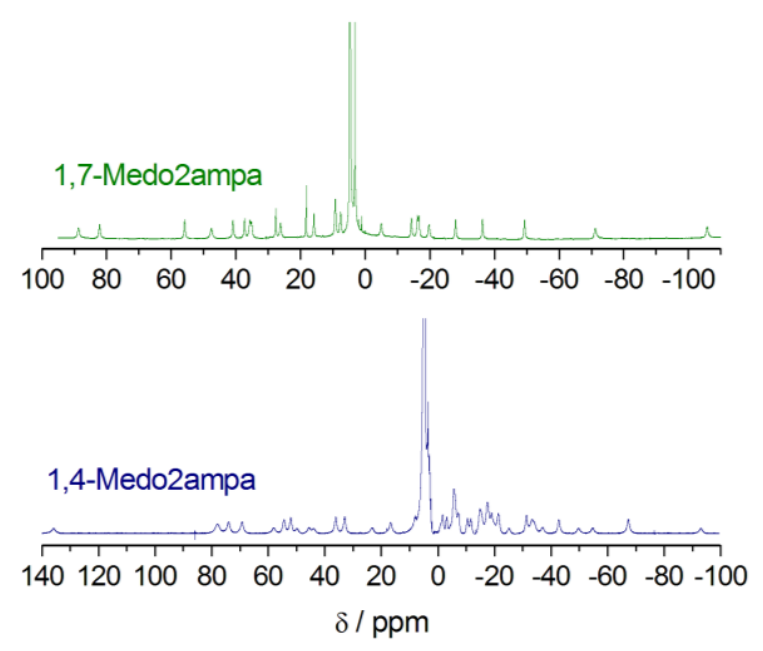

Figure 1. ${ }^{1} \mathrm{H}$ NMR spectra $\left(300 \mathrm{MHz}, \mathrm{D}_{2} \mathrm{O}, \mathrm{pH}=7.0\right)$ of the $\mathrm{Yb}^{3+}$ complexes of 1,7-Medo2ampa ${ }^{3-}$ and 1,4-Medo2ampa ${ }^{3-}$. 
The number of water molecules coordinated to the $\mathrm{Ln}^{3+}$ ion (q) were assessed by measuring the lifetimes of the $\mathrm{Eu}^{3+}\left({ }^{5} \mathrm{D}_{0}\right)$ and $\mathrm{Tb}^{3+}\left({ }^{5} \mathrm{D}_{4}\right)$ excited states in solutions of the complexes in $\mathrm{H}_{2} \mathrm{O}$ and $\mathrm{D}_{2} \mathrm{O}$ (Table 1). ${ }^{[26]}$ The absorption spectra of the complexes recorded in $\mathrm{H}_{2} \mathrm{O}$ solution show an absorption band with a maximum at $274 \mathrm{~nm}$ typical of the picolinate chromophore (Supporting Information). ${ }^{[20]}$ The emission spectra recorded under excitation through the ligand bands $\left(10^{-5} \mathrm{M}, \mathrm{pH} 7.0\right)$ show the ${ }^{5} \mathrm{D}_{0} \rightarrow{ }^{7} \mathrm{~F}_{\mathrm{J}}(\mathrm{J}=0-4)$ and ${ }^{5} \mathrm{D}_{4} \rightarrow{ }^{7} \mathrm{~F}_{\mathrm{J}}(\mathrm{J}=3-6)$ transitions characteristic of $\mathrm{Eu}^{3+}$ and $\mathrm{Tb}^{3+}$, respectively (Supporting Information).

Table 1. Luminescence lifetimes $(\tau, \mathrm{ms})$ and hydration numbers $(q)$ of the $\mathrm{Eu}^{3+}$ and $\mathrm{Tb}^{3+}$ complexes of 1,7-Medo2ampa and 1,4-Medo2ampa.

\begin{tabular}{llllll}
\hline & $\mathrm{Ln}^{3+}$ & $\tau\left(\mathrm{H}_{2} \mathrm{O}\right)$ & $\tau\left(\mathrm{D}_{2} \mathrm{O}\right)$ & $\Delta k_{\text {obs }}{ }^{[\mathrm{a}]}$ & $q^{[\mathrm{b}]}$ \\
\hline 1,7-Medo2ampa & $\mathrm{Eu}^{3+}$ & $0.569(3)$ & $1.69(1)$ & 1.17 & 1.1 \\
& $\mathrm{~Tb}^{3+}$ & $1.793(5)$ & $3.09(3)$ & 0.23 & 0.9 \\
1,4-Medo2ampa & $\mathrm{Eu}^{3+}$ & $0.584(2)$ & $1.327(4)$ & 0.96 & 0.9 \\
& $\mathrm{~Tb}^{3+}$ & $2.39(1)$ & $2.76(1)$ & 0.06 & 0.0
\end{tabular}

${ }^{[a]} \Delta k_{\text {obs }}=k_{\text {obs }}\left(\mathrm{H}_{2} \mathrm{O}\right)-k_{\mathrm{obs}}\left(\mathrm{D}_{2} \mathrm{O}\right), k_{\mathrm{obs}}=1 / \tau_{\mathrm{obs}}{ }^{[\mathrm{b}]} q(\mathrm{Eu})=1.2\left(\Delta k_{\mathrm{obs}}-0.25\right) ; q(\mathrm{~Tb})$ $=5.0\left(\Delta k_{\mathrm{obs}}-0.06\right)$.

The emission lifetimes of the $\mathrm{Eu}^{3+}\left({ }^{5} \mathrm{D}_{0}\right)$ and $\mathrm{Tb}^{3+}\left({ }^{5} \mathrm{D}_{4}\right)$ excited states of the complexes with 1,7-Medo2ampa ${ }^{3-}$ provide hydration numbers of $q=1.1$ and 0.9 using the equation of Beeby. ${ }^{[27]}$ These results indicate that the $\mathrm{Ln}^{3+}$ complexes of 1,7-do2ampa ${ }^{3-}$ contain a water molecule in the innercoordination sphere. This shows that the complexes are ninecoordinated in aqueous solution thanks to the octadentate binding of the ligand and the presence of a coordinated water molecule. Application of the same methodology to the complexes with 1,4-do2ampa $a^{3-}$ provides a hydration number of 0.9 for $\mathrm{Eu}^{3+}$ and a hydration number of 0.0 for $\mathrm{Tb}^{3+}$. These results suggest a rather abrupt change of the hydration number at the center of the lanthanide series.
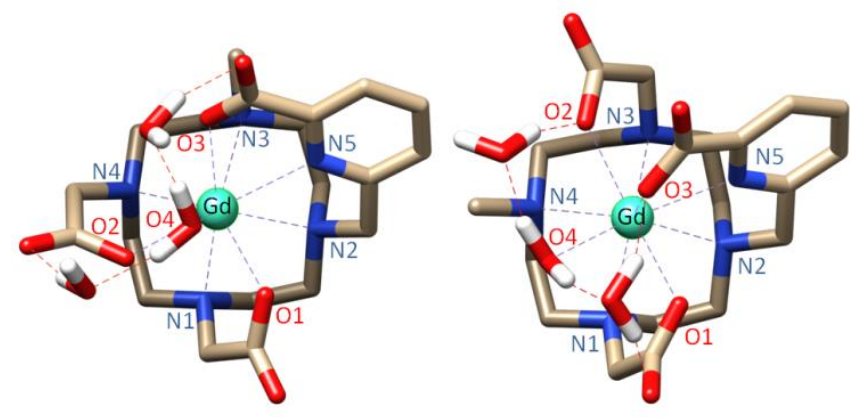

Figure 2. Structures of the $\left[\mathrm{Gd}(1,4-\mathrm{Medo} 2 \mathrm{ampa})\left(\mathrm{H}_{2} \mathrm{O}\right)\right] \cdot 2 \mathrm{H}_{2} \mathrm{O}$ (left) and $\left[\mathrm{Gd}(1,7-\mathrm{Medo} 2 \mathrm{ampa})\left(\mathrm{H}_{2} \mathrm{O}\right)\right] \cdot 2 \mathrm{H}_{2} \mathrm{O}$ (right) complexes optimized in aqueous solution at the TPSSh/LCRECP/6-31G(d) level.
To gain more insight into the structure of the complexes in aqueous solution we performed density functional theory (DFT) calculations at the TPSSh/LCRECP/6-31G(d) level. ${ }^{[28-30]}$ We have shown previously that a cluster/continuum approaches including explicitly two second-sphere water molecules provide a satisfactory description of the $\mathrm{Gd}-\mathrm{O}_{\text {water }}$ distances and accurate ${ }^{17} \mathrm{O}$ hyperfine coupling constants. ${ }^{[31]}$ The minimum energy conformation calculated for the SAP isomer of the [Gd(1,7-Medo2ampa) $\left.\left(\mathrm{H}_{2} \mathrm{O}\right)\right] \cdot 2 \mathrm{H}_{2} \mathrm{O}$ system (Figure 2) indicates octadentate binding of the ligand to the $\mathrm{Gd}^{3+}$ ion. The basal plane of the antiprism is described by the four nitrogen atoms of the cyclen unit, while the upper plane is defined by the $\mathrm{N}$ atom of the pyridyl unit, two oxygen atoms of the acetate pendant arms and a coordinated water molecule. The oxygen atom of the picolinate group is occupying the capping position. The mean twist angle of the upper and lower square faces amounts to $36.7^{\circ}$.

Since the [Yb(1,4-Medo2ampa)] complex exists in solution as a mixture of SAP and TSAP isomers we initially performed calculations on the $\left[\mathrm{Gd}(1,4-\mathrm{Medo2ampa})\left(\mathrm{H}_{2} \mathrm{O}\right)\right]$ system. These calculations provided the SAP and TSAP isomers as minimum energy conformations and predict a rather small Gibbs energy difference between them, favoring the TSAP form by only $\sim 2$ $\mathrm{kcal} \mathrm{mol}{ }^{-1}$. This energy reduces to $1.6 \mathrm{kcal} \mathrm{mol}^{-1}$ for the $\mathrm{Eu}^{3+}$ complex. Thus, it is likely that both the SAP and TSAP isomers are present in solution in the case of the $\mathrm{Gd}^{3+}$ complex. The broad signals observed in the ${ }^{1} \mathrm{H}$ NMR spectrum of the $\mathrm{Eu}^{3+}$ complex are in line with this hypothesis. Most likely the SAP isomer contains a water molecule coordinated to the $\mathrm{Ln}^{3+}$ ion, while the sterically more crowded TSAP isomer does not contain a coordinated water molecule. The latter species is largely dominating in the case of the $\mathrm{Tb}^{3+}$ complex, thus resulting in a $q$ value of 0.0 (Table 1).

The optimized structure of the SAP isomer of the [Gd(1,4-Medo2ampa) $\left.\left(\mathrm{H}_{2} \mathrm{O}\right)\right] \cdot 2 \mathrm{H}_{2} \mathrm{O}$ complex reveals octadentate binding of the ligand, with the coordinated water molecule occupying the capping position above the mean plane delineated by the four donor atoms of the pendant arms. The calculated $\mathrm{Gd}-\mathrm{O}_{\text {water }}$ distance $(2.549 \AA)$ is considerably longer than that calculated for $\left[\mathrm{Gd}(1,7-\mathrm{Medo} 2 \mathrm{ampa})\left(\mathrm{H}_{2} \mathrm{O}\right)\right] \cdot 2 \mathrm{H}_{2} \mathrm{O}(2.476$ $\AA)$. These data reflect a weaker binding of the water molecule when occupying a capping position in the coordination polyhedron. The calculated electron densities at the bond critical points $\left(\rho_{B C P}\right)$ of the $\mathrm{Gd}-\mathrm{O}_{\text {water }}$ bonds $(0.041$ and $0.034 \mathrm{a}$. u. for the complexes with 1,7-Medo2ampa ${ }^{3-}$ and 1,4-Medo2ampa ${ }^{3-}$, respectively) confirm that the coordinated water molecule is more tightly bound to the metal ion in the [Gd(1,7-Medo2ampa) $\left.\left(\mathrm{H}_{2} \mathrm{O}\right)\right]$ complex. ${ }^{[32]}$

Water exchange rates of the coordinated water molecules. The water exchange rates of the coordinated water molecules in the $\mathrm{Gd}^{3+}$ complexes were assessed by using ${ }^{17} \mathrm{O}$ NMR transverse relaxation rates and chemical shifts and ${ }^{1} \mathrm{H}$ relaxivity measurements. A combined analysis of the ${ }^{1} \mathrm{H}$ relaxivity and ${ }^{17} \mathrm{O}$ NMR data is required for an accurate estimation of the water exchange rates. ${ }^{[33]}$

The relaxivities $\left(r_{1 p}\right)$ of an aqueous solution of the complexes were first assessed at $20 \mathrm{MHz}$ and $25{ }^{\circ} \mathrm{C}$ (Figure 3). 
The relaxivity of $[\mathrm{Gd}(1,7-$ Medo2ampa)] measured in the $\mathrm{pH}$ range 5.1-7.2 (1.94 $\left.\mathrm{mM}^{-1} \mathrm{~s}^{-1}\right)$ is very low when compared with the relaxivities of $\mathrm{Gd}^{3+}$ complexes containing one inner-sphere water molecule such as $[\mathrm{Gd}(\mathrm{dota})]^{-}$. Below $\mathrm{pH} 5.1 r_{1 \mathrm{p}}$ increases due to the dissociation of the complex, the relaxivity observed at $\mathrm{pH}<2$ being very similar to that of $\left[\mathrm{Gd}\left(\mathrm{H}_{2} \mathrm{O}\right)\right]^{3+}$. ${ }^{[13]}$ Raising the $\mathrm{pH}$ above 7.2 results in a noticeable increase of $r_{1 \mathrm{p}}$, which reaches a value of $4.1 \mathrm{mM}^{-1} \mathrm{~s}^{-1}$ at $\mathrm{pH} 11.1$. This $\mathrm{pH}$ dependence of $r_{1 \mathrm{p}}$ is characteristic of systems having very slow water exchange rates around neutral $\mathrm{pH}$, so that the observed relaxivity is the result of the outer-sphere mechanism. Increasing the $\mathrm{pH}$ favors an acceleration of the water exchange by $\mathrm{OH}^{-}$catalysis of prototropic exchange. ${ }^{[12,34]}$ The relaxivity of [Gd(1,4-Medo2ampa)] at $\mathrm{pH} 7.0\left(20 \mathrm{MHz}\right.$ and $\left.25^{\circ} \mathrm{\circ}\right)$ is $(4.2$ $\left.\mathrm{mM}^{-1} \mathrm{~s}^{-1}\right)$, and therefore is considerably higher than that of the trans derivative. Again relaxivity increases below $\mathrm{pH} 4$ due to complex dissociation. Above $\mathrm{pH} 8$ the relaxivity slightly decreases, likely due to the formation of hydroxo complexes. ${ }^{[35]}$

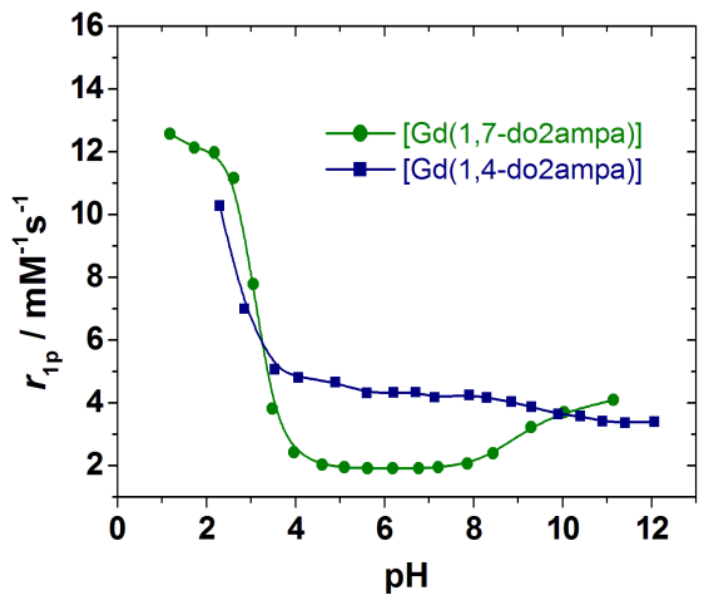

Figure 3. Plot of the ${ }^{1} \mathrm{H}$ relaxivities $(20 \mathrm{MHz}, 25 \stackrel{\circ}{\circ})$ of [Gd(1,7-Medo2ampa)] and $[\mathrm{Gd}(1,4-\mathrm{Medo} 2 \mathrm{ampa})]$ as a function of $\mathrm{pH}$.

Additional insight into the exchange dynamics of the coordinated water molecules in these $\mathrm{Gd}^{3+}$ complexes was obtained by measuring the temperature dependence of $r_{1 \mathrm{p}}(20$ $\mathrm{MHz}$, Figure 4). The relaxivity of [Gd(1,4-Medo2ampa)] decreases with increasing temperature, a behavior typical of small chelates in which fast rotation of the complex in solution limits proton relaxivity. Conversely, the temperature dependence of $r_{1 \mathrm{p}}$ measured for [Gd(1,7-Medo2ampa)] at $20 \mathrm{MHz}$ presents two distinct regions. From 5 to $30{ }^{\circ} \mathrm{C}$ the relaxivity is determined by the outer-sphere contribution, which increases as the temperature is reduced, while in the temperature range $40-80$ ${ }^{\circ} \mathrm{C} r_{1 \mathrm{p}}$ remains almost constant. This can be explained by an increasing contribution of the inner-sphere mechanism arising from a reduced $\tau_{\mathrm{m}}$ (acceleration of the water exchange rate), which is compensated by a decrease of the outer-sphere contribution and a faster rotation of the complex in solution at high temperatures.

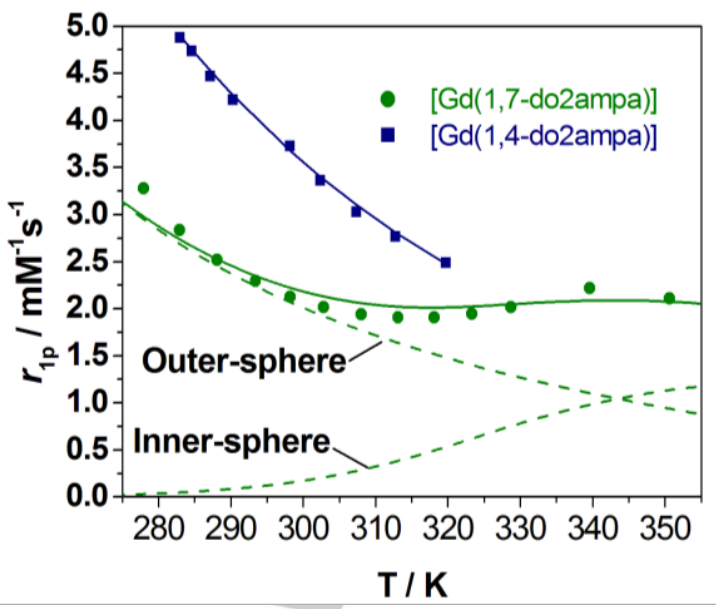

Figure 4. Plot of the ${ }^{1} \mathrm{H}$ relaxivities (20 MHz, $\mathrm{pH}=7$ ) of [Gd(1,7-Medo2ampa)] and $[\mathrm{Gd}(1,4-\mathrm{Medo} 2 \mathrm{mpa})]$ as a function of temperature. The solid lines represent the fits of the data as described in the text. The dotted lines represent the inner- and outer-sphere contributions calculated for [Gd(1,7-Medo2ampa)].

The ${ }^{1} \mathrm{H}$ nuclear magnetic relaxation dispersion (NMRD) profiles were recorded using aqueous solution of the complexes in the proton Larmor frequency range $0.01-70 \mathrm{MHz}$, corresponding to magnetic field strengths varying between 2.343 $\times 10^{-4}$ and $1.645 \mathrm{~T}$ (Figure 5). The NMRD profiles are typical of small $\mathrm{Gd}^{3+}$ chelates and show that the relaxivity of [Gd(1,4-Medo2ampa)] is higher than that of [Gd(1,7-Medo2ampa)] in the whole range of proton Larmor frequencies.

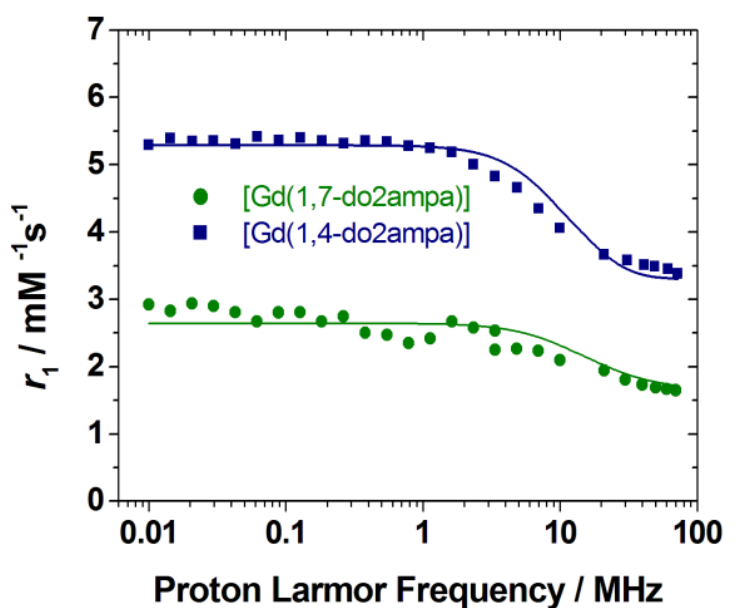

Figure 5. ${ }^{1} \mathrm{H}$ NMRD profiles recorded for [Gd(1,7-Medo2ampa)] and [Gd(1,4-Medo2ampa)] at $298 \mathrm{~K}$. The solid lines represent the fits of the data as described in the text. 
Table 2. Parameters obtained from the simultaneous analysis of the ${ }^{1} \mathrm{H}$ relaxivity and ${ }^{17} \mathrm{O}$ NMR data.

\begin{tabular}{lllll}
\hline Parameter & $1,7-M e d o 2 a m p a$ & $1,4-M e d o 2 a m p a$ & dota $^{4-[a]}$ & dotma $a^{4-[c]}$ \\
\hline$q^{298}$ & 1.0 & 0.55 & 1.0 & 1.0 \\
$k_{\mathrm{ex}}{ }^{298} / 10^{3} \mathrm{~s}^{-1}$ & $8.8 \pm 1.8$ & $11970 \pm 3400$ & 4100 & 11800 \\
$\tau_{\mathrm{m}}{ }^{298} / \mu \mathrm{s}$ & 114 & 0.083 & 0.24 & 0.085 \\
$\Delta H^{\ddagger} / \mathrm{kJ} \mathrm{mol}^{-1}$ & $51.9 \pm 4.4$ & $29.8 \pm 3.3$ & 49.8 & 44.5 \\
$A / \hbar / 10^{6} \mathrm{rad} \mathrm{s}^{-1}$ & $-3.65^{[\mathrm{b}]}$ & $-2.65^{[\mathrm{b}]}$ & -3.7 & -3.7 \\
$\tau_{\mathrm{R}}{ }^{298} / \mathrm{ps}$ & $80 \pm 27$ & $80^{[\mathrm{b}]}$ & 77 & 81 \\
$\tau_{\mathrm{V}^{298} / \mathrm{ps}}$ & $15.9 \pm 2.2$ & $11.4 \pm 1.7$ & 11 & 7.9 \\
$\Delta^{2} / 10^{19} \mathrm{~s}^{-2}$ & $9.96 \pm 1.94$ & $15.7 \pm 3.4$ & 1.6 & 1.7 \\
$\mathrm{r}_{\mathrm{GdH}} / \AA$ & $2.918^{b}$ & $3.068^{b}$ & 3.1 & 3.1 \\
$D_{\mathrm{GdH}}{ }^{298} / 10^{-10} \mathrm{~m}^{2} \mathrm{~s}^{-1}$ & $21.9 \pm 1.3$ & $20.0^{[b]}$ & 20.2 & 22.4 \\
\hline
\end{tabular}

[a] Data from ref. 13. [b] Parameters estimated independently using DFT calculations. [c] Data from ref. 42 . $H_{4}$ dotma $=\alpha, \alpha$ ', $\alpha$ ", $\alpha$ "'-tetramethyl1,4,7,10-tetraazacyclododecane-1,4,7,10-tetraacetic acid.

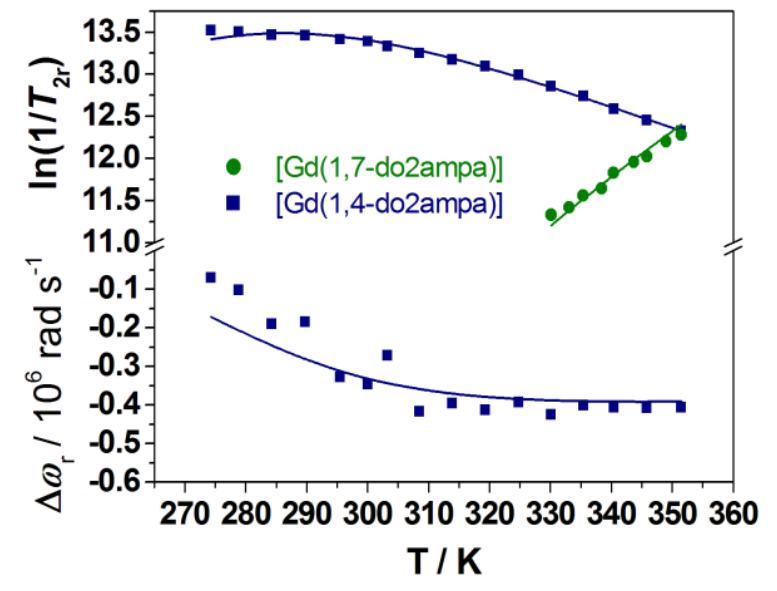

Figure 6. Reduced transverse ${ }^{17} \mathrm{O}$ relaxation rates and chemical shifts measured at $11.74 \mathrm{~T}(\mathrm{pH}=7.2)$. The solid lines correspond to the fits of the data as described in the text. For [Gd(1,7-Medo2ampa)] the paramagnetic effect on $T_{2}$ was significant only at high temperatures due to the slow water exchange, while effects in chemical shifts were negligible. The reduced relaxation rates and chemical shifts are defined as $\left.1 / T_{2 \mathrm{r}}=\left[1 / c_{\mathrm{Gd}} / 55.5\right)\right]\left[1 / T_{\mathrm{i}}\right.$ $\left.1 / T_{\mathrm{iA}}\right]$ and $\left.\Delta \omega_{\mathrm{r}}=\left[1 / \mathrm{CGd}_{\mathrm{Gd}} / 55.5\right)\right]\left(\omega-\omega_{\mathrm{A}}\right)$, where $T_{\mathrm{i}}$ and $T_{2 \mathrm{~A}}$ are the paramagnetic and diamagnetic relaxation times, $\omega$ and $\omega_{A}$ are the paramagnetic and diamagnetic chemical shifts and $c_{\mathrm{Gd}}$ is the concentration of the complex.

The paramagnetic effect of the $\mathrm{Gd}^{3+}$ ion on the ${ }^{17} \mathrm{O}$ chemical shifts of [Gd(1,7-Medo2ampa)] was found to be negligible. However, the transverse ${ }^{17} \mathrm{O}$ relaxation rates $1 / T_{2 \mathrm{r}}$ increase upon increasing temperature, which is typical of systems in the slow exchange regime (Figure 6). The temperature dependence of the $1 / T_{2 r}$ data measured for [Gd(1,4-Medo2ampa)] evidences a fast water exchange regime in the whole temperature range investigated, although the data display a maximum at the low temperature side that signals the commence of a changeover from a fast water exchange regime at high temperatures to a slow exchange regime. The temperature dependence of the reduced chemical shifts $\left(\Delta \omega_{r}\right)$ measured for [Gd(1,4-Medo2ampa)] are in line with the $1 / T_{2 r}$ data.

A simultaneous analysis of the ${ }^{1} \mathrm{H}$ relaxivity and ${ }^{17} \mathrm{O}$ NMR data was carried out using well-established procedures. ${ }^{[13]}$ Given the large number of parameters that enter the fit of the NMRD and ${ }^{17} \mathrm{O}$ NMR data, some them had to be fixed in order to achieve a reliable analysis. The number of water molecules in the inner coordination sphere of $\mathrm{Gd}^{3+}$ was fixed to $q=1$ in [Gd(1,7-Medo2ampa)] on the basis of the luminescence measurements described above. However, the ${ }^{17} \mathrm{O} 1 / T_{2 \mathrm{r}}$ and chemical shift data obtained for [Gd(1,4-Medo2ampa)] clearly point to an equilibrium involving a nine coordinate species with one inner-sphere water molecule and an eight-coordinate $q=0$ species. This is in line with the hydration numbers obtained from luminescence lifetime measurements for the complexes with the $\mathrm{Eu}^{3+}$ and $\mathrm{Tb}^{3+}$ ions, which flank $\mathrm{Gd}^{3+}$ in the lanthanide series. Hydration equilibria were found to be relatively common in $\mathrm{Gd}^{3+}$ complexes. An accurate determination of the equilibrium constant at different temperatures was accomplished in some cases by analyzing the ${ }^{5} \mathrm{D}_{0} \leftarrow{ }^{7} \mathrm{~F}_{0}$ transition observed in the absorption spectra of the $\mathrm{Eu}^{3+}$ analogues. ${ }^{[36]}$ These studies provided hydration entropies of $\Delta S^{\circ} \sim 40 \mathrm{~J} \mathrm{~mol}^{-1} \mathrm{~K}^{-1}$ for hydration equilibria defined as: ${ }^{[37]}$

$$
\left[\mathrm{Ln}(\mathrm{L})\left(\mathrm{H}_{2} \mathrm{O}\right)\right] \leftrightarrows[\mathrm{Ln}(\mathrm{L})]+\mathrm{H}_{2} \mathrm{O}
$$

Where $L$ represents a polyaminopolycarboxylate ligand and charges are omitted for simplicity. Thus, we included $\Delta S^{\circ}$ and $\Delta H^{\circ}$ for reaction (1) in $[\mathrm{Gd}(1,4-$ Medo2ampa)] as a fitting parameters. The distance of closest approach for the outersphere contribution $a_{\mathrm{GdH}}$ was fixed at $4.0 \AA$, while the distance between the proton nuclei of the coordinated water molecule and the $\mathrm{Gd}^{3+}$ ion $\left(r_{\mathrm{GdH}}\right)$ were fixed to the values obtained from our DFT calculations (Table 2). The values of the ${ }^{17} \mathrm{O}$ hyperfine coupling constants $(A / \hbar$, Table 2$)$ were fixed to the values estimated using DFT calculations following the previously reported methodology (TPSSh/SCRECP/EPR-III level). ${ }^{[2,38,39]}$ Finally, the values of the activation energies for the diffusion 
coefficient $\left(E_{D G d H}\right)$, the rotational correlation time $\left(E_{\mathrm{r}}\right)$ and the activation energy for the modulation of the zero-field-splitting $\left(E_{\mathrm{v}}\right)$ were fixed to common values $\left(22,20\right.$ and $1 \mathrm{~kJ} \mathrm{~mol}^{-1}$, respectively). ${ }^{[13]}$ The value of $\tau_{\mathrm{R}}{ }^{298}$ of [Gd(1,4-Medo2ampa)] was fixed to that obtained for [Gd(1,7-Medo2ampa)], a reasonable assumption considering the identical size of the two complexes.

The values obtained for the parameters determining the electron spin relaxation (the electronic correlation time for the modulation of the zero-field-splitting interaction, $\tau_{v}$, and the mean square zero-field-splitting energy, $\Delta^{2}$ ) and the diffusion coefficient $D_{\mathrm{GdH}}{ }^{298}$ are close to those reported for other $\mathrm{Gd}^{3+}$ complexes, while the values of the rotational correlation time are consistent with the size of the complexes (Table 2). ${ }^{[13]}$

The results of the fit obtained for [Gd(1,4-Medo2ampa)] provided a reaction enthalpy of $\Delta H^{\circ}=5.7 \pm 3.0 \mathrm{~kJ} \mathrm{~mol}^{-1}$ for reaction 1 , and a reaction entropy of $\Delta S^{\circ}=20.6 \pm 10.2 \mathrm{~J} \mathrm{~mol}^{-1}$ define a hydration $n$ number of 0.55 at $25{ }^{\circ} \mathrm{C}$. This value is in very good agreement with the average of the hydration numbers determined for the $\mathrm{Eu}^{3+}$ and $\mathrm{Tb}^{3+}$ complexes (Table 1). The hydration number varies from 0.63 at the lowest temperature investigated $\left(1^{\circ} \mathrm{C}\right)$ to 0.55 at $78 \stackrel{\circ}{\circ} \mathrm{C}$. The positive $\Delta S^{\circ}$ value is in line with values obtained for the hydration equilibria of different $\mathrm{Eu}^{3+}$ complexes.

The parameters determined for the water exchange in [Gd(1,7-Medo2ampa)] $\left(k_{\mathrm{ex}}{ }^{298}=8.8 \pm 1.8 \times 10^{3} \mathrm{~s}^{-1}, \Delta H^{\prime}=51.9 \pm\right.$ $4.4 \mathrm{~kJ} \mathrm{~mol}^{-1}$ ) provide a mean residence time of the coordinated water molecule at $298 \mathrm{~K}$ of $\tau_{\mathrm{m}}{ }^{298}=114 \mu \mathrm{s}$. This value represents the lowest water exchange rate of the coordinated water molecule for a $\mathrm{Gd}^{3+}$ complex, being very similar to the one reported for the SAP isomer of $\left[\mathrm{Eu}(\operatorname{dotam})\left(\mathrm{H}_{2} \mathrm{O}\right)\right]^{3+}\left(k_{\mathrm{ex}}{ }^{298}=9.4 \times\right.$ $\left.10^{3} \mathrm{~s}^{-1}\right),{ }^{[40]}$ and somewhat longer than those reported for $\mathrm{Gd}^{3+}$ complexes of dota-tetraamides $\left(9.9-330 \times 10^{3} \mathrm{~s}^{-1}\right) \cdot{ }^{[12]}$ The very low water exchange rates observed for dota-tetraamide complexes are explained in terms of the rather strong $\mathrm{Gd}$-water interaction in +3 charged complexes that increases the energy cost for the departure of the water molecule in a dissociative activated exchange mechanism. Thus, the low water exchange rate in $\left[\mathrm{Gd}(1,7-\mathrm{Medo} 2 \mathrm{ampa})\left(\mathrm{H}_{2} \mathrm{O}\right)\right]$ is surprising considering the neutral charge of the complex. The inner-sphere water molecule in this complex occupies one of the coordination positions in one of the square faces of the square antiprism coordination polyhedron, while in dota-like complexes the water molecule is capping that square face. Thus, water molecules occupying the capping position provide weaker Gd-water bonds than water molecules in positions defining the square antiprismatic coordination. As a result, water molecules in the capping position are expected to experience faster water exchange rates. This is confirmed by the fast water exchange rate determined for $[\mathrm{Gd}(1,4$-Medo2ampa $)]\left(k_{\mathrm{ex}}{ }^{298}=1.2 \pm 0.3 \times 10^{7}\right.$ $\left.\mathrm{s}^{-1}\right)$, which is ca. three times higher than that of $[\mathrm{Gd}(\mathrm{dota})]^{-}$and very similar to that reported for $[\mathrm{Gd}(\mathrm{dotma})]^{-}$(Table 2). ${ }^{\left[{ }^{[2]}\right.}$ Both $[\mathrm{Gd}(\mathrm{dota})]^{-}$and $[\mathrm{Gd}(\text { dotma })]^{-}$contain a water molecule coordinated in a capping position. However, the population of $[\mathrm{Gd}(\text { dotma })]^{-}$in solution is dominated by the TSAP isomer ( 81\%), while for [Gd(dota)] the SAP isomer represents ca. $83 \%$ of the overall population. In both [Gd(dota) ] and [Gd(dotma)] the exchange rate of the coordinated water molecule in the TSAP isomer was reported to be ca. 7 times higher than in the SAP form. Thus, the extremely low water exchange rate of [Gd(1,7-Medo2ampa)] must be related to the position that the water molecule occupies in the coordination polyhedron. We want to emphasize that the presence of a hydration equilibrium in $[\mathrm{Gd}(1,4-$ Medo2ampa)] introduces some uncertainty on the parameters obtained from the analysis of ${ }^{17} \mathrm{O}$ NMR and NMRD data. Nevertheless, our data provide clear-cut evidence of a much faster water exchange rate in [Gd(1,4-Medo2ampa)] compared to [Gd(1,7-Medo2ampa)].

The labile capping bond phenomenon is in line with the water exchange rates measured for a $\mathrm{Gd}^{3+}$ complex with a heptadentate triamide cyclen-based ligand. Indeed, monodentate binding of phosphate and acetate to this complex, presumably occupying a coordination position in one square face of the polyhedron, was shown to increase the water exchange rate of the water molecule by two orders of magnitude. ${ }^{[43]}$ These results have also implication for the analysis of water exchange rates of bis-hydrated complexes. For instance, the bis-hydrated complex $\left[\mathrm{Gd}(\mathrm{do} 3 \mathrm{a})\left(\mathrm{H}_{2} \mathrm{O}\right)_{2}\right]$ contains a water molecule coordinating at the apical position and a second water molecule at one of the vertexes of the square antiprismatic polyhedron. Previous computational studies suggested that these water molecules should present considerably different exchange rates, ${ }^{[32]}$ while analysis of ${ }^{17} \mathrm{O}$ NMR data using a three-site exchange model failed to provide individual exchange rates for the two coordinated water molecules. ${ }^{[43]}$ Recently, Dolg et al. reported computational studies that pointed out that water molecules occupying capping positions within the $\mathrm{Ln}^{3+}$ coordination environment are inherently labile. ${ }^{[44]}$ This phenomenon was attributed to environmental effects, as the bond with a ligand occupying a capping position is hindered by the environment. While these studies provided some hints pointing to the labile capping bond phenomenon, the study presented in this work provide unequivocal experimental evidence for this effect.

\section{Conclusions}

A rational design of two ligands possessing identical donor atoms sets allowed to tune the position of the coordinated water molecule, which occupies either a capping position or a position in one of the square faces of the square antiprismatic polyhedron. We have found that while [Gd(1,7-Medo2ampa)] contains a coordinated water molecule in aqueous solution, the [Gd(1,4-Medo2ampa)] analogue presents an equilibrium in solution involving $q=1$ and $q=0$ species. Nevertheless, the water exchange rate measured for the fraction of complex containing a coordinated water molecule is three orders of magnitude higher than that of [Gd(1,7-Medo2ampa)]. Thus, the present contribution provides solid evidences demonstrating that water ligands occupying capping positions in the coordination polyhedron are intrinsically labile. The labile capping bond phenomenon demonstrated here represents a significant advance for the rational design of optimized $\mathrm{Gd}^{3+}$-based contrast agents and CEST probes for MRI applications in clinical 
diagnostics and pre-clinical research. Furthermore, it is likely that this effect is not only operating in $\mathrm{Ln}^{3+}$ complexes, but also in complexes with other metal ions, paving the way to a more rational control of the reactivity of metal complexes.

\section{Acknowledgements}

M.R.-F., D.E.-G., T. R-B. and C.P.-I. thank Ministerio de Economía y Competitividad (CTQ2009-10721/PPQ, CTQ201343243-P and CTQ2015-71211-REDT) and Xunta de Galicia (CN2012/011) for generous financial support. M.B. and F.C. are grateful to Università del Piemonte Orientale for a research grant. R.T. thanks the University of Brest and the CG29 for a post-doctoral research grant. The research presented in this work was supported by the EU and co-financed by the European Regional Development Fund under the project GINOP-2.3.2.-152016-00008 and by the he Hungarian Scientific Research Fund (OTKA K-109029 and K-120224 projects). This work was also supported by the János Bolyai Research Scholarship (Gy. T.) of the Hungarian Academy of Sciences. The authors are indebted to Centro de Supercomputación of Galicia (CESGA) for providing the computer facilities.

Keywords: Gadolinium • MRI • Density Functional Calculations • NMR spectroscopy• Water Exchange

[1] L. Helm, A. E. Merbach, Chem. Rev. 2005, 105, 1923-1959.

[2] a) N. P. E. Barry, P. J. Sadler, Pure Appl. Chem. 2014, 86, 1897-1910. b) D. T. Richens, Chem. Rev. 2005, 105, 1961-2002. c) E. Balogh, W. H. Casey, Prog. Nucl. Magn. Reson. Spectrosc. 2008, 53, 193-207.

[3] a) J. Maigut, R. Meier, A. Zahl, R. van Eldik, J. Am. Chem. Soc. 2008, 130, 14556-14569. b) A. Brausam, J. Maigut, R. Meier, P. A. Szilagyi, H.-J. Buschmann, W. Massa, Z. Homonnay, R. van Eldik, Inorg. Chem. 2009, 48, 7864-7884. c) R. van Eldik, Coord. Chem. Rev. 2007, 251 1649-1662.

[4] A. Cusanelli, U. Frey, D. T. Richens, A. E. Merbach, J. Am. Chem. Soc. 1996, 118, 5265-5271.

[5] P. Caravan, E. Toth, A. Rochenbauer, A. E. Merbach, J. Am. Chem. Soc. 1999, 121, 10403-10409.

[6] a) C. Cossy, L. Helm, A. E. Merbach, Inorg. Chem. 1988, 27, 19731979. b) C. Cossy, L. Helm, A. E. Merbach, Inorg. Chem. 1989, 28, 2699-2703.

[7] a) The Chemistry of Contrast Agents in Medical Magnetic Resonance Imaging, A. E. Merbach, L. Helm, É. Tóth, Eds. 2nd ed., Wiley, New York, 2013. b) M. C. Heffern, L. M. Matosziuk, T. J. Meade, Chem. Rev. 2014, 114, 4496-4539.

[8] a) P. Caravan, J. J. Ellison, T. J. McMurry, R. B. Lauffer, Chem. Rev. 1999, 99, 2293-2352. b) Y. Song, E. K. Kohlmeir, T. J. Meade, J. Am. Chem. Soc. 2008, 130, 6662-6663.

[9] a) P. Caravan, Chem. Soc. Rev. 2006, 35, 512-523. b) S. Aime, M. Botta, M. Fasano, E. Terreno, Acc. Chem. Res. 1999, 32, 941-949. c) B. N. Siriwardena-Mahanama, M. J. Allen, Molecules 2013, 18, 93529381. d) A. T. Preslar, G. Parigi, M. T. McClendon, S. S. Sefick, T. J. Moyer, C. R. Haney, E. A. Waters, K. W. MacRenaris, C. Luchinat, S. I. Stupp, T. J. Meade, ACS Nano 2014, 8, 7325-7332.

[10] a) S. Aime, S. Geninatti Crich, E. Gianolio, G. B. Giovenzana, L. Tei, E. Terreno, Coord. Chem. Rev. 2006, 250, 1562-1579. b) E. Terreno, D. Delli Castelli, S. Aime, Contrast Media Mol. Imaging 2010, 5, 78-98.
[11] a) E. Vinogradov, A. D. Sherry, R. E. Lenkinski, J. Magn. Reson. 2013 229, 155-172. b) P. C. M. van Zijl, N. N. Yadav, Magn. Reson. Med. 2011, 65, 927-948. c) X. Yang, N. N. Yadav, X. Song, S. R. Banerjee, H. Edelman, I. Minn, P. C. M. van Zijl, M. G. Pomper, M. T. McMahon, Chem. Eur. J. 2014, 20, 15824-15832.

[12] S. Aime, A. Barge, J. I. Bruice, M. Botta, J. A. K. Howard, J. M. Moloney, D. Parker, A. S. de Sousa, M. Woods, J. Am. Chem. Soc. 1999, 121, 5762-.

[13] D. H. Powell, O. M. Ni Dhubhghaill, D. Pubanz, L. Helm, Y. S. Lebedev, W. Schlaepfer, A. E. Merbach, J. Am. Chem. Soc. 1996, 118, 93339346.

[14] M. Mato-Iglesias, C. Platas-Iglesias, K. Djanashvili, J. A. Peters, E. Toth, E. Balogh, R. N. Muller, L. Vander Elst, A. de Blas, T. RodriguezBlas, Chem. Commun. 2005, 4729-4731.

[15] a) F. A. Dunand, S. Aime, A. E. Merbach, J. Am. Chem. Soc. 2000, 122 1506-1512. b) W. T. Dixon, J. Ren, A. J. M. Lubag, J. Ratnakar, E. Vinogradov, I. Hancu, R. E. Lenkinski, A. D. Sherry, Magn. Reson. Med 2010, 63, 625-632.

[16] a) W. S. Fernando, A. F. Martins, P. Zhao, Y. Wu, G. E. Kiefer, C Platas-Iglesias, A. D. Sherry, Inorg. Chem. 2016, 55, 3007-. b) N Cakic, T. Savic, J. Stricker-Shaver, V. Truffault, C. Platas-Iglesias, C Mirkes, R. Pohmann, K. Scheffler, G. Angelovski, Chem. Commun. 2016, 52, 9224-.

[17] S. Laurent, L. Vander Elst, F. Botteman, R. N. Muller, Eur. J. Inorg. Chem. 2008, 4369-.

[18] a) R. Ruloff, E. Toth, R. Scopelliti, R. Tripier, H. Handel, A. E. Merbach Chem. Commun. 2002, 2630-2631. b) S. Laus, R. Ruloff, E. Toth, A. E. Merbach, Chem. Eur. J. 2003, 9, 3555-3566. c) J. Kotek, P. Lebduskova, P. Hermann, L. Vander Elst, R. N. Muller, C. F. G. C. Geraldes, T. Maschmeyer, I. Lukes, J. A. Peters, Chem. Eur. J. 2003, 9 5899-5915. d) A. Congreve, D. Parker, E. Gianolio, M. Botta, Dalton Trans. 2004, 1441-1445

[19] A. L. Thompson, D. Parker, D. A. Fulton, J. A. K. Howard, S. U. Pandya, H. Puschmann, K. Senanayake, P. A. Stenson, A. Badari, M. Botta, S. Avedano, S. Aime, Dalton Trans. 2006, 5605-5616.

[20] M. Regueiro-Figueroa, B. Bensenane, E. Ruscsak, D. Esteban-Gómez, L. J. Charbonniere, G. Tircso, I. Toth, A. de Blas, T. Rodriguez-Blas, C. Platas-Iglesias, Inorg. Chem. 2011, 50, 4125-4141.

[21] M. Le Baccon, F. Chuburu, L. Toupet, H. Handel, M. Soibinet, I. Dechamps-Olivier, J.-P. Barbier, Aplincourt, New J. Chem. 2001, 25, 1168-1174.

[22] J. Rohovec, R. Gyepes, I. Cisarova, J. Rudovsky, I. Lukes, Tetrahedron Lett. 2000, 41, 1249-1253.

[23] M. Mato-Iglesias, A. Roca-Sabio, Z. Palinkas, D. Esteban-Gomez, C. Platas-Iglesias, E. Toth, A. de Blas, T. Rodriguez-Blas, Inorg. Chem. 2008, 47, 7840-7851.

[24] a) C. Li, W.-T. Wong, J. Org. Chem. 2003, 68, 2956-2959. b) W. J. Kruper, Jr., P. R. Rudolf, C. A. Langhoff, J. Org. Chem. 1993, 58, 3869-3876.

[25] a) L. S. Natrajan, A. J. L. Villaraza, A. M. Kenwright, S. Faulkner, Chem Commun. 2009, 6020—6022. b) M. Main, M. M. Meloni, M. Jauregui, D. Sykes, S. Faulkner, A. M. Kenwright, J. S. Snaith, Chem. Commun. 2008, 5212-5214.

[26] a) W. D. W. Horrocks, Jr., D. R. Sudnick, J. Am. Chem. Soc. 1979, 101, 334-340. b) R. M. Supkowski, W. D. W. Horrocks, Jr. Inorg. Chim. Acta 2002, 340, 44-48.

[27] A. Beeby, I. M. Clarkson, R. S. Dickins, S. Faulkner, D. Parker, L. Royle, A. S. de Sousa, J. A. G. Williams, M. Woods, J. Chem. Soc. Perkin Trans. 2 1999, 493-503.

[28] M. Dolg, H. Stoll, A. Savin, H. Preuss, Theor. Chim. Acta, 1989, 75 , 173-194.

[29] J. Tao, J. P. Perdew, V. N. Staroverov, G. E. Scuseria, Phys. Rev. Lett. 2003, 91, 146401.

[30] M. J. Frisch, G. W. Trucks, H. B. Schlegel, G. E. Scuseria, M. A. Robb, J. R. Cheeseman, G. Scalmani, V. Barone, B. Mennucci, G. A. 
Petersson, et al. Gaussian 09, Revision D.01, Gaussian, Inc: Wallingford CT, 2009.

[31] D. Esteban-Gomez, A. de Blas, T. Rodriguez-Blas, L. Helm, C. PlatasIglesias, ChemPhysChem 2012, 13, 3640-3650.

[32] M. Regueiro-Figueroa, C. Platas-Iglesias, J. Phys. Chem. A 2015, 119, 6436-6445.

[33] J. A. Peters, Contrast Media Mol. Imaging 2016, 11, 160-168.

[34] S. Aime, A. Barge, M. Botta, D. Parker, A. S. De Sousa, J. Am. Chem. Soc. 1997, 119, 4767-4768.

[35] C. Platas, F. Avecilla, A. de Blas, T. Rodríguez-Blas, C. F. G. C. Geraldes, E. Toth, A. E. Merbach, J.-C. G. Bünzli, J. Chem. Soc. Dalton Trans. 2000, 611-618.

[36] N. Graeppi, D. H. Powell, G. Laurenczy, L. Zekany, A. E. Merbach, Inorg. Chim. Acta 1995, 235, 311-326.

[37] a) C. Platas-Iglesias, D. M. Corsi, L. Vander Elst, R. N. Muller, D. Imbert, J.-C. G. Bünzli, E. Toth, T. Maschmeyer, J. A. Peters, Dalton Trans. 2003, 727-737. b) E. Balogh, M. Mato-Iglesias, C. Platas-
Iglesias, E. Toth, K. Djanashvili, J. A. Peters, A. de Blas, T. RodriguezBlas, Inorg. Chem. 2006, 45, 8719-8728.

[38] M. Dolg, H. Stoll, H. Preuss, J. Chem. Phys. 1989, 90, 1730-1734.

[39] N. Rega, M. Cossi, V. Barone, J. Chem. Phys. 1996, 105, 1106011067.

[40] F. A. Dunand, R. S. Dickins, D. Parker, A. E. Merbach, Chem. Eur. J. 2001, 7, 5160-5167.

[41] J. I. Bruce, R. S. Dickins, L. J. Govenlock, T. Gunnlaugsson, S. Lopinski, M. P. Lowe, D. Parker, R. D. Peacock, J. J. B. Perry, S. Aime, M. Botta, J. Am. Chem. Soc. 2000, 112, 9674-9684.

[42] S. Aime, M. Botta, Z. Garda, B. E. Kucera, G. Tircso, V. G. Young, M. Woods, Inorg. Chem. 2011, 50, 7955-7965.

[43] E. Toth, O. M. N. Dhubhghaill, G. Besson, L. Helm, A. E. Merbach, Magn. Reson. Chem. 1999, 37, 701-708.

[44] a) J. Zhang, N. Heinz, M. Dolg, Inorg. Chem. 2014, 53, 7700-7708. b) J. Zhang, M. Dolg, J. Phys. Chem. A 2015, 119, 774-780. 


\section{Entry for the Table of Contents}

\section{FULL PAPER}

We demonstrate with the aid of two macrocyclic ligands that the exchange rate of the $\mathrm{Gd}^{3+}$-bound water molecules is affected dramatically by their coordination environment, with water molecules occupying a capping position being considerably more labile.
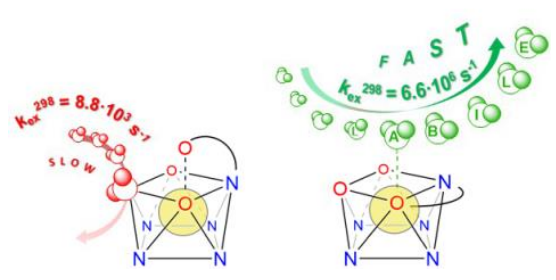

Aurora Rodríguez-Rodríguez, Martín Regueiro-Figueroa, David EstebanGómez, Teresa Rodríguez-Blas, Véronique Patinec, Raphaël Tripier, Gyula Tircsó, Fabio Carniato, Mauro Botta, and Carlos Platas-Iglesias

Page No. - Page No.

Definition of the Labile Capping Bond Effect in Lanthanide Complexes 